\title{
Cognitive Errors and Anxiety in School Aged Children
}

\author{
Erros Cognitivos e Ansiedade em Crianças em Idade Escolar
}

\author{
Ana I. Freitas Pereira ${ }^{*}, a$, Luísa Barros ${ }^{a} \&$ Denisa Mendonça ${ }^{b}$ \\ ${ }^{a}$ Universidade de Lisboa, Lisboa, Portugal \& ${ }^{b}$ Universidade do Porto, Porto, Portugal
}

\begin{abstract}
Cognitive models of emotional disorders emphasize the role of biased information processing in the psychological functioning of anxious individuals. So far, the role of cognitive errors in problems of childhood anxiety disorders has received little empirical attention. This study analyzes the relations between cognitive errors and symptoms of anxiety in a sample of school aged children. The sample, comprised by 205 children (8 to 13 years old), answered the Children's Negative Cognitive Errors Questionnaire (CNCEQ) and the Screen for Child Anxiety Related Emotional Disorders - Revised (SCARED-R). Results show a positive and statistically significant relationship between cognitive errors and symptoms of anxiety, suggesting the importance of modifying these cognitive processes for prevention and intervention targeting anxiety problems in school aged children.

Keywords: Cognitive errors, anxiety, children.

Resumo

Os modelos cognitivos das perturbações emocionais enfatizam o papel do processamento enviesado de informação em indivíduos ansiosos. Até ao momento, o papel dos erros cognitivos nos problemas de ansiedade na infância tem recebido pouca atenção empírica. Este estudo analisa a relação entre erros cognitivos e sintomatologia de ansiedade em crianças. A amostra é composta por 205 crianças (8-13 anos), que responderam ao Questionário de Erros Cognitivos para Crianças (CNCEQ) e à versão revista do Questionário de Avaliação de Perturbações Emocionais Relacionadas com a Ansiedade em Crianças (SCARED-R). Os resultados, que revelam uma relação positiva e estatisticamente significativa entre erros cognitivos e sintomatologia de ansiedade, sugerem a importância da modificação destes processos cognitivos na intervenção dirigida aos problemas de ansiedade em crianças.

Palavras chave: Erros cognitivos, ansiedade, crianças.
\end{abstract}

Anxiety disorders are the most prevalent problems in childhood and adolescence (Albano, Chorpita, \& Barlow, 2003), affecting between 5.7 and $17.7 \%$ of children and youth (Costello \& Angold, 1995). The high prevalence of anxiety disorders in childhood and its high social costs underlie the need to study the etiology of anxiety disorders. Knowledge of risk and maintenance factors of anxiety disorders is fundamental to the development of preventive strategies and effective intervention.

Cognitive models emphasize the role of cognitive aspects in the development of emotional disorders. Beck's cognitive model (Beck, Rush, Shaw, \& Emery, 1979) introduced the concept of cognitive distortions or errors by assigning to these cognitions a central role in the psychological functioning of depressed individuals, and later in the psychological functioning of anxious individuals (Beck, Emery, \& Greenberg, 1985).

\footnotetext{
"Acknowledgments: This study was supported by a grant awarded to the first author by Fundação para a Ciência e Tecnologia (SFRH/BPD/63960/2009). The authors thank all the schools, families and children that participated in this study and made it possible.

Endereço para correspondência: Faculdade de Psicologia, Universidade de Lisboa, Alameda da Universidade, Lisboa, Portugal 1649-013. E-mail: aipereira@fp.ul.pt
}

These cognitive errors are characterized by a negative bias in the interpretations of events which are not based on reality. Even in those cases where there is a more realistic basis for these interpretations, the repetitive nature and the self-deprecating and extremely negative content, causes them to have a significant negative impact on the thoughts, emotions and behavior of individuals, affecting their well-being and adaptive functioning.

According to Beck's cognitive model, these cognitive errors are the result of relatively stable negative cognitive schemas, formed during childhood, which guide how information and events are interpreted. This model also proposes that the content of these cognitive schemes is different in depressed individuals compared to anxious individuals. More specifically, depressed individuals selectively attend and process negative information and minimize positive information, while anxious individuals selectively attend and process information related to threat and personal vulnerability.

Most studies analyzing the role of cognitive biases in emotional disorders have focused their attention on the problems of depressed adults. More recently, research on cognitive models of anxiety has been conducted with children and adolescents to study the biases in different stages of information processing - attention, interpreta- 
tion and memory - and how these different biases interact to maintain high anxiety (Daleiden \& Vasey, 1997; Muris \& Field, 2008; Watts \& Weems, 2006).

Kendall's (1985) cognitive theory proposes that pathological anxiety results from the chronic hyperactivation of schemes related to personal vulnerability and danger. This hyperactivation would lead individuals, when faced with some kind of threat, novelty or ambiguity, to direct their attentional and processing resources to the information relevant to the threat, resulting in different cognitive distortions. These cognitive distortions would in turn lead to maladaptive thoughts and behaviors.

Studying the role of these processes in the development and maintenance of anxiety disorders in childhood is dependent on the existence of valid and reliable instruments that assess children's anxiety as well as cognitive factors associated with it. Most of the methods used to evaluate anxiety and cognition in anxious individuals were originally developed for adults (Alfano, Beidel, \& Turner, 2002; Schniering, Hudson, \& Rapee, 2000; Silverman \& Ollendick, 2005). This assessment is strongly influenced by factors relating to cognitive, metacognitive and linguistic development (Campbell \& Rapee, 1996; Schniering et al., 2000). However one should not assume that children experience and report anxiety the same way as adults. Thus, these instruments should be sensitive to developmental issues and the interpretation of results must take into account norms that consider different manifestations of these phenomena throughout a person's development.

Fortunately there are several well-validated instruments for assessing anxiety in children from the school-age group onwards (Manassis et al., 2009). These children, unlike younger children, can both monitor and name their emotions, although sometimes more anxious children may have greater difficulty with this task, especially since their families tend to discourage the discussion of emotions (Suveg, Zeman, Flannery-Schroeder, \& Cassano, 2005).

Regarding the assessment of cognitive factors related to anxiety, the evaluation is also very dependent on the same developmental dimensions. Preschool children do not have the metacognitive skills that enable them to monitor and report their thoughts. Some studies show that the ability of introspection increases significantly between 5 and 7 years of age (J. H. Flavell, Green, \& E. L. Flavell, 2000) and inner speech knowledge is acquired in the first years of school perhaps as a result of repetitive cognitive activities such as reading or silent counting.

Therefore, children's access to their internal representations and thoughts, as well as their ability to report them, increases considerably during the first years of school. Some authors argue that it is only possible to assess with some accuracy the thoughts and cognitive processes from this age-group onwards. However, despite progress in various skills, concrete operational thinking prevails during the school years, keeping the child focused on the present and limiting the capacity for abstract thought. Consequently, methodologies aimed at assessing cognitive factors in school aged children, should refer the child to concrete situations that facilitate the recognition of characteristic thoughts and cognitive processes associated with these situations.

The Children's Negative Cognitive Error Questionnaire was developed by Leitenberg, Leonard and Carroll-Wilson (1986) to assess four negative cognitive errors of Beck's proposed theory. Each item describes a specific situation in a relevant domain (social, academic and athletic) for most children in this age range and a negative interpretation of this situation, representative of the four thinking errors evaluated by the questionnaire. Catastrophizing, that is, anticipating that the outcome of an event will be very negative or catastrophic; overgeneralization, which happens when one assumes that the negative outcome of an experience applies to the same experience or similar experiences in the future; personalizing, which is reflected by assuming personal responsibility for negative events or the interpretation of these events as if they had a personal meaning; and finally, selective abstraction, which occurs when attention is focused specifically on the negative aspects of an experience, instead of more neutral or positive aspects of experiences.

More recently, some empirical studies that focused on the relationship between cognitive errors and anxiety in children and young people, demonstrated a positive relationship between cognitive errors and anxiety in clinical samples (Ostrander, Nay, Anderson, \& Jensen, 1995; Weems, Berman, Silverman, \& Saavedra, 2001) and in community samples (Epkins, 1996; Leitenberg et al., 1986; Weems, Costa, Watts, Taylor, \& Cannon, 2007). Studies have also shown that there is some specificity of cognitive errors depending on the clinical diagnosis. Accordingly, a study (Weems et al., 2001) carried out with a clinical sample of children and adolescents, found a significant association between cognitive errors and anxiety for all cognitive errors, except for the error of selective abstraction, after controlling for the effect of depression. These results, in conjunction with those of other studies with community samples (Maric, Heyne, van Widenfelt, \& Westenberg, 2011), are consistent with Beck's specificity hypothesis since they suggest that selective abstraction is a cognitive error more characteristic of depression than of anxiety. In another study, with a community sample (Epkins, 1996), it was observed that the group of children with high levels of social anxiety (and low levels of dysphoria) had significantly higher levels of personalizing and overgeneralization than the group with high levels of dysphoria (and low levels of social anxiety). On the other hand, this second group also exhibited more selective abstraction errors than the group with high levels of social anxiety, although the difference was not statistically significant.

Given the significant changes in cognitive abilities that occur during childhood and adolescence, it is important that the understanding of the influence of cognitive factors in anxiety is made in light of a developmental focus (Broeren 
\& Muris, 2009). Some developmental changes in relation to self-centeredness $v s$. decentration, self- perception, concrete thinking vs. abstract thinking and causal attributions determine changes in how children and youth process information and events (Ostrander et al., 1995). However, little empirical attention has been given to this aspect. Few studies (eg, Broeren \& Muris, 2009; Muris, Mayer, Vermeulen, \& Hiemstra, 2007; Muris, Merckelbach, Meesters, \& van den Brand, 2002) have investigated the relationship between cognitive development and the intensity and frequency of different manifestations of anxiety in infants (specific fears, generalized anxiety, etc.), but we could not find any study that examines how changes in the level of children's social-cognitive skills influence the cognitive processes associated with anxiety. Some studies, without directly assessing social-cognitive skills, sought to investigate the influence of age on cognitive errors, but the results of these studies are inconsistent. For example, one study found a greater number of cognitive errors in older children $\left(8^{\text {th }}\right.$ grade $)$ than in younger children $\left(4^{\text {th }}\right.$ and $6^{\text {th }}$ grade; Cole \& Turner, 1993), while another conducted with a community sample (Leitenberg et al., 1986) found that younger children ( $4^{\text {th }}$ grade) reported more cognitive errors than older children (6th and $8^{\text {th }}$ grade) and further studies (Epkins, 1996; Kingery, Kepley, Ginsburg, \& Walkup, 2009) found no statistically significant differences.

In addition to age differences in the frequency of different types of cognitive errors, it is also important to explore if the role of cognitive factors in emotional disorders changes with development. Although cognitive schemas that underlie the different types of cognitive errors have their origin in childhood, these schemas may be more unstable and permeable to changes or environmental events in the early childhood years. Some authors (Ostrander et al., 1995) suggest that the role of negative cognitions in the development of emotional disorders only assumes a greater relevance when children approach adolescence.

Studies concerning the relationship of gender with cognitive errors are also very scarce. A study of a clinical sample of depressed adolescents (Kingery et al., 2009) observed more cognitive errors in female adolescents.

This study seeks to contribute to a better understanding of cognitive errors in school aged children and their relationship with anxiety symptoms. A first objective of this study is to analyze the effect of age and gender in different types of cognitive errors. Given the scarcity of studies and inconsistent results, this goal is merely exploratory.

A second objective of this study is to analyze the relationship between cognitive errors and anxiety symptoms in school aged children. According to the results of previous studies, we hypothesize the existence of a statistically significant positive association between anxiety and cognitive errors. Differences between children with high and low levels of anxiety, considering the different types of cognitive errors, will also be examined. It is expected that children with high levels of anxiety, as compared to children with low levels of anxiety, will globally present more cognitive errors, and the differences between groups will be smaller for selective abstraction error.

\section{Method}

\section{Participants}

The sample comprised 205 children aged 8 to 13 years, with a mean age of 10 years old $(S D=1.24)$. The sample was composed of $49 \%$ of female children, with $78 \%$ of the children belonging to intact nuclear families. Taking into account the parent's occupation and education, the sample was characterized according to three socio-economic levels: $34 \%$ low, $35 \%$ medium and $31 \%$ high-medium and high. The majority of the participants lived in semi-urban and urban areas. The children attended the $3^{\text {rd }}, 4^{\text {th }}, 5^{\text {th }}$ or $6^{\text {th }}$ grade of six private and public schools.

\section{Instruments}

The Children's Negative Cognitive Error Questionnaire (CNCEQ; Leitenberg et al., 1986; Portuguese version from Pereira \& Barros, 2010). The CNCEQ, a selfreport questionnaire with 24-items, was developed to assess four types of cognitive errors derived theoretically: catastrophizing, overgeneralization, personalizing, and selective abstraction. Each item presents a hypothetical vignette and a negative interpretation of the vignette that represents one of the four cognitive errors evaluated. Children are asked to which degree they would interpret the hypothetical situation in a similar way on a 5-point scale which ranges from 1 ("Nothing like I would think") to 5 ("Exactly what I would think"). In this study scores for each of the cognitive error types and a total cognitive distortion score were obtained. Higher values correspond to more cognitive errors. The internal consistency for this sample shows a high internal consistency for the overall score $(\alpha=.89)$ and moderate values for each of the cognitive error subscales $(\alpha=.63-.70)$. Mean values of inter-item also show a good internal consistency $(r=.22-.28)$. Internal consistency results are very similar to the results obtained with the original questionnaire (Leitenberg et al., 1986).

Screen for Child Anxiety Related Emotional Disor-ders - revised version (SCARED-R; Muris, Merckelbach, Schmidt, \& Mayer, 1999; Portuguese version from Pereira, $\&$ Barros, 2010). The SCARED-R is a self-report questionnaire with 69 items evaluating different dimensions of anxiety disorders in children: separation anxiety disorder, generalized anxiety disorder, panic disorder, social phobia, school phobia, specific phobia, obsessive-compulsive disorder and acute or posttraumatic stress disorder. Children have to rate how frequently they experience each symptom on a 3-point scale: 0 (never or almost never), 1 (sometimes), 2 (often). In this study only the overall score was considered. The Portuguese version (Pereira \& Barros, 2010) of the questionnaire shows high levels of internal consistency $(\alpha=.91)$ for the overall score. 


\section{Data Collection Procedure}

Before data collection, we asked the General Direction for Innovation and Curriculum Development for permission to conduct the study in the six schools. We then contacted the school board of these schools to ask for their collaboration. All the teachers of the classes participating in the study were contacted and the study's objectives were clarified. Teachers sent out the consent forms to the parents (via the children) so they could authorize the participation of their child in the study. Only those children whose parents gave their informed consent participated in the study. The adherence rate $(85 \%)$ was high.

The instruments were administered collectively, in the classroom, in the presence of the researcher. The questionnaire administration had a maximum duration of 45 minutes.

\section{Data Analyses Procedure}

The assumptions required to conduct the various statistical tests were verified and $p$ - values below .05 were considered as indicating significant results.

To accomplish the first objective of our study, a multivariate analysis of variance (MANOVA) was conducted to analyze the age group (8-9, 10-13 years) and gender effects on the four cognitive errors. Firstly, the relationships between cognitive errors and anxiety were studied using Pearson correlations. Subsequently, with the objective of analyzing the differences between high-anxious and lowanxious children regarding cognitive errors, two groups of children from the global sample were selected. The group of high anxious children was composed of children who scored above the $85^{\text {th }}$ percentile on the global scale of SCARED-R and the group of low anxious children was composed of children who scored below the $25^{\text {th }}$ percentile. Percentile 85 was chosen because it is considered a good cut-off point to discriminate children with anxiety disorder from children without anxiety disorder (Simon \& Bogels, 2009). Then, a repeated measures analysis of variance (ANOVA) with one within-subjects factor (Negative Cognitive Error Type [catastrophizing, overgeneralization, personalizing, and selective abstraction]) and one between-subjects factor (Anxious Group Condition [High and Low Anxious Group]) was performed. In the presence of significant effects, multiple comparisons with Bonferroni correction were conducted.

\section{Results}

\section{Cognitive Errors: Gender and Age Effects}

The values for the various types of cognitive errors in terms of gender and age are presented in Table 1.

Table 1

Mean and Standard Deviation Values in the Subscales and Global Scale of the Children's Negative Cognitive Error Questionnaire by Gender and Age Groups

\begin{tabular}{lcccccccccc}
\hline & \multicolumn{9}{c}{ Female } & \multicolumn{3}{c}{ Male } & \multicolumn{3}{c}{ Total } \\
\cline { 2 - 12 } & \multicolumn{3}{c}{$8-9$ years } & \multicolumn{1}{c}{$10-13$ years } & \multicolumn{2}{c}{$8-9$ years } & $10-13$ years & & \\
& $M$ & $S D$ & $M$ & $S D$ & $M$ & $S D$ & $M$ & $S D$ & $M$ & $S D$ \\
\hline Catastrophizing & 12.8 & 4.7 & 14.8 & 5.0 & 11.0 & 4.0 & 12.7 & 5.3 & 13.1 & 5.0 \\
Personalizing & 14.3 & 3.9 & 16.2 & 4.8 & 12.5 & 4.3 & 14.3 & 5.5 & 14.6 & 5.0 \\
Selective abstraction & 12.4 & 3.6 & 14.9 & 4.1 & 10.6 & 4.1 & 13.1 & 5.0 & 13.2 & 4.6 \\
Overgeneralization & 12.9 & 5.1 & 14.9 & 5.4 & 12.3 & 4.9 & 13.5 & 5.3 & 13.7 & 5.3 \\
Total/Global & 52.4 & 14.6 & 60.8 & 16.0 & 46.4 & 15.0 & 53.6 & 18.8 & 54.6 & 17.3 \\
\hline
\end{tabular}

The results suggest that in the global sample children do not report many cognitive errors.

A MANOVA was conducted to analyze the age group (8-9, 10-13 years) and gender effects in the four cognitive errors. Results show a significant gender effect, $F(4,197)=$ $2.60, p=.04$, and age effect, $F(4,197)=3.60, p=.007$ and an absence of a significant interaction. As we can see in Table 2 , the results of the subsequent univariate tests show a significant effect of the age group in the four cognitive errors. Older children present more cognitive errors than younger children. Also, there was a significant gender effect in three of the four cognitive errors, catastrophizing, personalizing, and selective abstraction. Female children showed more cognitive errors than male children.
Table 2

ANOVAs: Gender and Age Group Effects in Catastrophizing, Personalizing, Selective Abstraction and Overgeneralization

\begin{tabular}{llrr}
\hline & Fators & $F(1,204)$ & $p$ \\
\hline Catastrophizing & Sex Effect & 6.7 & .01 \\
& Age Effect & 6.4 & .01 \\
Personalizing & Sex Effect & 6.7 & .01 \\
Selective abstraction & Age Effect & 6.5 & .01 \\
& Sex Effect & 7.2 & .01 \\
& Age Effect & 14.6 & .001 \\
Overgeneralization & Sex Effect & 1.7 & n.s. \\
& Age Effect & 4.0 & .05 \\
\hline
\end{tabular}


Pereira, A. I. F., Barros, L. \& Mendonça, D. (2012). Cognitive Errors and Anxiety in School Aged Children.

\section{Cognitive Errors and Anxiety}

The correlations between anxiety and all the cognitive errors are statistically significant and of moderate magnitude. The results are as expected, demonstrating higher levels of anxiety associated with more cognitive errors.

Table 3

Pearson Correlations between Negative Cognitive Errors and Anxiety Reported by the Child

\begin{tabular}{ll}
\hline & SCARED-R \\
\hline Catastrophizing & $.43^{* * *}$ \\
Personalizing & $.37^{* * *}$ \\
Selective abstraction & $.30^{* * *}$ \\
Overgeneralization & $.39^{* * *}$ \\
Total & $.44^{* * *}$ \\
\hline
\end{tabular}

$* * *<.001$

Table 4
The results from the repeated ANOVA measures show significant effects for negative cognitive errors type, $F(3,75)=3.97, p=.01$ and a significant interaction between negative cognitive errors type and anxious group condition, $F(3,75)=3.84, p=.01$. Results support the existence of differences in cognitive errors in function of the type of error. The interaction effect supports the idea that high anxious and low anxious children have different profiles of cognitive errors.

To test the simple effects in the presence of the interaction, several multiple comparisons were conducted (Table 4). The comparison of the two profiles shows that for the low anxious group there are no significant differences between the different negative cognitive error types. In a different way, the results show significant differences between cognitive error types for the high anxious group. This group has lower levels of the cognitive error selective abstraction compared to personalizing and overgeneralization. Additionally, it can be observed that the low anxious group presents fewer cognitive errors than the high anxious group for all of the cognitive errors.

Cognitive Errors and Anxiety Group Condition: Mean Values (Standard Deviation) and Multiple Comparisons

\begin{tabular}{lccccc}
\hline & $\begin{array}{c}\text { Catastrophizing } \\
(\mathrm{C})\end{array}$ & $\begin{array}{c}\text { Personalizing } \\
(\mathrm{P})\end{array}$ & $\begin{array}{c}\text { Selective } \\
\text { abstraction } \\
(\mathrm{SA})\end{array}$ & $\begin{array}{c}\text { Overgeneralization } \\
(\mathrm{O})\end{array}$ & $\begin{array}{c}\text { Multiple } \\
\text { comparisons } \\
\text { by line* }\end{array}$ \\
\hline Low anxious (LA, $n=43)$ & $10.7(3.9)$ & $12.1(3.6)$ & $11.8(4.2)$ & $11.1(4.3)$ & n.s. \\
High anxious (HA, $n=36)$ & $16.3(5.4)$ & $17.0(5.7)$ & $14.6(5.3)$ & $16.6(6.1)$ & SA $<$, O \\
Multiple comparision by column* & LA $<$ HA & LA $<$ HA & LA $<$ HA & LA $<$ HA & \\
\hline
\end{tabular}

Note. ${ }^{*}$ Results from multiple comparisons when means are significantly different from each other, $p<.05$.

\section{Discussion}

The present study tried to shed light on the relationship between cognitive errors and anxiety symptoms in school aged children. Results support cognitive models of anxiety (Beck et al., 1985; Kendall, 1985), which emphasize the importance of cognitive errors in the functioning of anxious individuals.

The study of these cognitive processes in childhood raises some questions that have not been well explored. One question that arises pertains to the age at which children develop more stable cognitive styles that can influence the way they attend and process the information and life events, in a more systematic and consistent manner. Some authors suggest that it is only in early adolescence that these cognitive styles become more stable (Ostrander et al., 1995).

The results of this study show a statistically significant effect of age on different cognitive errors. Older children have significantly more cognitive errors than younger children and this effect occurs for all cognitive errors. These results are in line with the results of some studies
(Cole \& Turner, 1993), but inconsistent with others (Leitenberg et al., 1986). One explanation for these results is related to the higher reflective capacities of older children. Older children have more cognitive skills which enable them to reflect on events, seek explanations for them and think about the consequences of these events and the relationship between various events. Therefore, we can hypothesize that a more elaborated thinking about situations enhances the probability of cognitive errors occurring in a more systematic way, partially supporting the hypothesis that this biased processing can become more stable with age. These data seem to suggest that with the onset of adolescence it becomes essential to include in the treatment of anxiety disorders a component of intervention directed towards the modification of dysfunctional cognitive patterns. After these cognitive patterns are established, they operate as a filter that directs attentional and processing resources for threat related information and promotes the avoidant behavior typically observed in anxious individuals (Kendall, 1985). These patterns tend to crystallize over time, becoming more rigid and difficult to modify. Thus, it seems important to evaluate these 
negative cognitive styles early on and to address them in the treatment of anxious children.

Furthermore, a statistically significant gender effect in three of the cognitive errors: catastrophizing, personalizing and selective abstraction, was observed. This result is consistent with the study of Kingery et al. (2009) conducted with a clinical sample of depressed adolescents.

Epidemiological studies show a higher prevalence of anxiety disorders and depression in females and a possible explanation for this occurrence is the difference between men and women in factors that can promote an increased psychological vulnerability for such disorders. For example, the results of a longitudinal study of 1100 adults (Nolen-Hoeksema, Larson, \& Grayson, 1999) reveal that ruminative coping styles are more common in women and that these cognitive styles mediate gender differences in depression. Thus, in the same manner that these gender differences in coping styles may explain gender differences in anxiety and depression, it is also possible that the greater frequency of cognitive errors in female children may contribute to this difference.

In accordance with what was expected, there was a positive and statistically significant relationship between all types of cognitive errors and anxiety. A comparison of extreme groups provides additional information about the types of errors that are most relevant in anxiety problems. In the comparative analysis of profiles of children with high and low levels of anxiety, significant differences between groups for all cognitive errors were observed. However, in the group of children with high levels of anxiety, there are fewer errors of selective abstraction compared to the cognitive errors, personalizing and overgeneralization. This is consistent with results from other studies which demonstrate that selective abstraction, characterized by a focus on negative aspects and by the minimization of the positive, is more characteristic of depression (Epkins, 1996; Weems et al., 2001; Weems et al., 2007). The higher levels of personalizing and overgeneralization are consistent with the specificity hypothesis of Beck. It is expected that personalizing is an error characteristic of children with anxiety problems since anxious individuals are focused on self-threat and personal vulnerability and have an inflated sense of responsibility. Similarly, since overgeneralization is an error focused on future events, one would also expect it to happen more often in anxious children.

In general, the results suggest that cognitive errors are important factors discriminating children with high levels of anxiety from children with low levels of anxiety. These results support the relevance of Beck's cognitive model, originally developed to explain emotional disorders in adults, for a better understanding of emotional disorders in children.

The study of cognitive models of emotional disorders has more than just a theoretical interest, it has important and practical implications in the evaluation and treatment of childhood psychopathology. These models suggest the potential change processes that should be included in psychotherapy with children (Kendall \& Treadwell, 2007). The results of this study suggest that maladaptive cognitive styles associated with anxiety can be identified in school aged children. Consequently it is important to include instruments that measure such factors within this stage of development and to include strategies aimed at modifying cognitive styles in the treatment of children with anxiety disorders. The inclusion of evaluation measures such as the Cognitive Errors Questionnaire can provide important clues to the therapist and the child, thus enabling the identification of the child's most common cognitive biases that should be targeted for the therapeutic intervention.

The majority of cognitive-behavioral intervention programs have a component directed at the modification of maladaptive cognitions (Chu \& Harrison, 2007). More recently, some studies have also gathered evidence that suggests that the change of cognitive processes is a significant mediator of therapeutic change in anxious children (Kendall \& Treadwell, 2007; Muris, Mayer, den Edel, Wamelen, \& Roos, 2009). However future studies should determine which are the most appropriate therapeutic strategies to reduce cognitive errors in school aged children. There are different therapeutic strategies for the modification of anxious cognitions, including self-instructional training and cognitive restructuring. In self-instructional training, anxious children are taught to replace their anxious self-talk by more positive coping self-talk. Cognitive restructuring involves monitoring and identifying negative automatic thoughts and cognitive errors, disputing these thoughts and identifying alternative thoughts. Until now it is unknown if these same strategies are equally effective in modifying cognitive errors in school aged children.

Despite the contributions of this study, it is important to point out its limitations, including the cross-sectional design and the recurrence of a single informant. Thus, it seems important to gather more empirical evidence, with longitudinal and multi-informant studies, in order to clarify the role of cognitive errors in the development of anxiety problems in children. Moreover, age is one of the proxy indicators of development, so for a better understanding of the role of development in anxiety disorders, it is important to use other more specific indicators of cognitive and socio-cognitive development in future studies.

\section{References}

Albano, A. M., Chorpita, B. F., \& Barlow, D. H. (2003). Childhood anxiety disorders. In E. J. Mash \& R. A. Barkley (Eds.), Child Psychopathology (2 ${ }^{\text {nd }}$ ed., pp. 279-329). New York: The Guilford Press.

Alfano, C. A., Beidel, D. C., \& Turner, S. M. (2002). Cognition in childhood anxiety: Conceptual, methodological, and developmental issues. Clinical Psychology Review, 22, 12091238.

Beck, A.T., Emery, G., \& Greenberg, R. L. (1985). Anxiety disorders and phobias: A cognitive perspective. New York: Guilford Press. 
Pereira, A. I. F., Barros, L. \& Mendonça, D. (2012). Cognitive Errors and Anxiety in School Aged Children.

Beck, A. T., Rush, A. J., Shaw, B. F., \& Emery, G. (1979) Cognitive therapy of depression. New York: Guilford.

Broeren, S., \& Muris, P. (2009). The relation between cognitive development and anxiety phenomena in children. Journal of Child and Family Studies, 18, 702-709.

Campbell, M. A., \& Rapee, R. M. (1996). Current issues in the assessment of anxiety in children and adolescents: A developmental perspective. Behavior Change, 13, 185-193.

Chu, B. C., \& Harrison, T. L. (2007). Disorder-specific effects of CBT for anxious and depressed youth: A meta-analysis of candidate mediators of change. Clinical Child family Psychology Review, 10, 352-372.

Cole, D. A., \&Turner, J. E. (1993). Models of cognitive mediation and moderation in child depression. Journal of Abnormal Psychology, 102, 271-281.

Costello, E. J., \& Angold, A. (1995). The epidemiology of childhood anxiety disorders. In J. S. March (Ed.), Anxiety disorders in children and adolescents (pp. 109-124). New York: The Guilford Press.

Daleiden, E. L., \& Vasey, M. W. (1997). An informationprocessing perspective on childhood anxiety. Clinical Psychology Review, 17, 407-429.

Epkins, C. C. (1996). Cognitive specificity and affective confounding in social anxiety and dysphoria in children. Journal of Psychopathology and Behavioral Assessment, 18, 83-101.

Flavell, J. H., Green, F. L., \& Flavell, E. L. (2000). Development of children's awareness of their own thoughts. Journal of Cognition and Development, 1, 97-112.

Kendall, P. C. (1985). Toward a cognitive-behavioral model of child psychopathology and a critique of related interventions. Journal of Abnormal Child Psychology, 13, 357-372.

Kendall, P. C., \& Treadwell, K. R. H. (2007). The role of selfstatements as a mediator in treatment for youth with anxiety disorders. Journal of Consulting and Clinical Psychology, 75, 3080-3389.

Kingery, J. N., Kepley, H. O., Ginsburg, G. S., \& Walkup, J. T. (2009). Factor structure and psychometric properties of the children's negative cognitive error questionnaire with a clinically depressed adolescent sample. Journal of Clinical Child and Adolescent Psychology, 38(6), 768-780.

Leitenberg, H., Leonard, W. Y., \& Carroll-Wilson, M. (1986). Negative cognitive errors in children: Questionnaire development, normative data, and comparisons between children with and without self-reported symptoms of depression, low self-esteem, and evaluation anxiety. Journal of Consulting and Clinical Psychology, 54, 528-536.

Manassis, K., Mendlowitz, S., Kreindler, D., Lumsden, C., Sharpe, J., Simon, M. D., et al. (2009). Mood assessment via animated characters: A novel instrument to evaluate feelings in young children with anxiety disorders. Journal of Clinical Child \& Adolescent Psychology, 38, 380-389.

Maric, M., Heyne, D. A., van Widenfelt. B. M., \& Westenberg, P. M. (2011). Distorded cognitive processing in youth: The structure of negative cognitive errors and their associations with anxiety. Cognitive Therapy Research, 35, 11-20.

Muris, P., \& Field, A. P. (2008). Distorted cognition and pathological anxiety in children and adolescents. Cognition and Emotion, 22(3), 395-421.

Muris, P., Mayer, B., den Edel, M., Roos, T., \& van Wamelen, J. (2009). Predictors of change following cognitive-behavioral treatment of children with anxiety problems: A preliminary investigation on negative automatic thoughts and anxiety control. Child Psychiatry Human Development, 40, 139-151.
Muris, P., Mayer, B., Vermeulen, L., \& Hiemstra, H. (2007). Theory of mind, cognitive development, and children's interpretation of anxiety-related physical symptoms. Behaviour Research and Therapy, 45, 2121-2132.

Muris, P., Merckelbach, H., Meesters, C., \& van den Brand, K. (2002). Cognitive development and worry in normal children. Cognitive Therapy and Research, 26, 775-787.

Muris, P., Merckelbach, H., Schmidt, H., \& Mayer, B. (1999). The revised version of the Screen for Child Anxiety Related Emotional Disorders (SCARED-R): Factor structure in normal children. Personality and Individual Differences, 26, 99-112.

Nolen-Hoeksema, S., Larson, J., \& Grayson, C. (1999). Explaining the gender difference in depressive symptoms. Journal of Personality and Social Psychology, 77, 1061-1072.

Ostrander, R., Nay, W. R., Anderson, D., \& Jensen, J. (1995). Developmental and symptoms specificity of hopelessness, cognitive errors, and attributional bias among clinic-referred youth. Child Psychiatry and Human Development, 26, 97-111.

Pereira, A. I., \& Barros, L. (2010). Portuguese version of the revised version of the Screen for Child Anxiety Related Emotional Disorders (SCARED-R). Unpublish manuscript, Faculty of Psychology, University of Lisbon, Portugal.

Schniering, C. A., Hudson, J. L., \& Rapee, R. M. (2000). Issues in the diagnosis and assessment of anxiety disorders in children and adolescents. Clinical Psychology Review, 20, 453-478.

Silverman, W., \& Ollendick, T. H. (2005). Evidence-based assessment of anxiety and its disorders in children and adolescents. Journal of Clinical Child and Adolescent Psychology, 34, 380-411.

Simon, E., \& Bögels, S. M. (2009). Screening for anxiety disorders in children. European Child and Adolescent Psychiatry, 18, 625-634. Retrieved from http://dx.doi.org/10.1007\% 2Fs00787-009-0023-x

Suveg, C., Zeman, J., Flannery-Schroeder, E., \& Cassano, M. (2005). Emotion socialization in families of children with an anxiety disorder. Journal of Abnormal Child Psychology, 33, 145-155.

Watts, S. E., \& Weems, C. F. (2006). Associations among selective attention, memory bias, cognitive errors and symptoms of anxiety in youth. Journal of Abnormal Child Psychology, 34, 841-852.

Weems, C. F., Berman, S. L., Silverman, W. K., \& Saavedra, L. (2001). Cognitive errors in youth with anxiety disorders: The linkages between negative cognitive errors and anxious symptoms. Cognitive Therapy and Research, 25, 559-575.

Weems, C. F., Costa, N. M., Watts, S. E., Taylor, L. K., \& Cannon, M. F. (2007). Cognitive errors, anxiety sensitivity, and anxiety control beliefs: Their unique and specific association with childhood anxiety symptoms. Behavior Modification, 31, 174-201. 